\title{
Azole-resistance in Aspergillus terreus and closely related species, an overseen problem?
}

Zoran Tamara, Division of Hygiene and Medical Microbiology, Innsbruck, Austria Sartori Bettina, Division of Hygiene and Medical Microbiology, Innsbruck, Austria Houbraken Jos, Westerdijk Fungal Biodiversity Institute, Utrecht, Netherlands Risslegger Brigitte, Division of Hygiene and Medical Microbiology, Innsbruck, Austria Lass-Flörl Cornelia, Division of Hygiene and Medical Microbiology, Innsbruck, Austria Lackner Michaela, Division of Hygiene and Medical Microbiology, Innsbruck, Austria

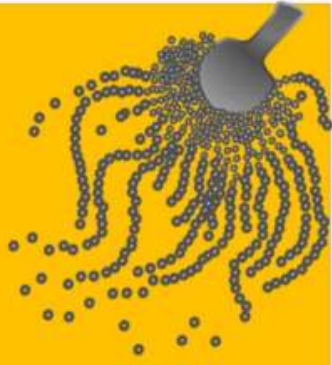

\section{hmm}

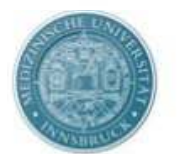

MEDIZINISCHE UNIVERSITÄT

Michaela.Lackner@i-med.ac.at

\section{Objective}

Invasive mold infections associated with Aspergillus species are a significant cause of mortality in immunocompromised patients. The most frequently occurring aetiological pathogens are members of the Aspergillus section Fumigati followed by members of the section Terrei.

The frequency of Aspergillus terreus and related (cryptic) species in clinical specimens, as well as the percentage of azole-resistant strains remains to be studied.

\section{Material \& Methods}

A global set $(n=498)$ of section Terrei isolates was molecularly identified (beta-tubulin), tested for antifungalsusceptibility (Etest

\begin{tabular}{|c|c|c|}
\hline Anthungal apent & $\begin{array}{c}\text { Mic } \\
\text { s }\end{array}$ & $(\mathrm{m} g / \mathrm{l})$ \\
\hline Plossconaroie & $\leq 0.125$ & $>0250$ \\
\hline Venoonarale: & $\leq 1.000$ & $>2000$ \\
\hline 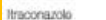 & $\leqslant 000$ & $=2000$ \\
\hline
\end{tabular}
and EUCAST: posaconazole, voriconazole, and itra-conazole), and resistant phenotypes were correlated with point mutations in the cyp51A gene.

\section{Results}

\begin{tabular}{|c|c|c|c|}
\hline Country & $\begin{array}{c}\text { All isolates studied } \\
\text { (\%) }\end{array}$ & $\begin{array}{l}\text { A. terreus sensu stricto } \\
(\%)\end{array}$ & 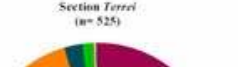 \\
\hline Austria & 10.5 & 10.9 & \\
\hline France & 9.1 & 9.1 & \\
\hline Germany & 13.7 & 15.9 & \\
\hline Italy & 4.9 & 5.7 & \\
\hline Spain & 2.3 & 1.5 & \\
\hline UK & 12.5 & 12.5 & \\
\hline Iran & 0.0 & 0.0 & \\
\hline Israel & 0.0 & 0.0 & 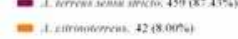 \\
\hline India & 0.0 & 0.0 & $=$ \\
\hline Brazil & 0.0 & 0.0 & 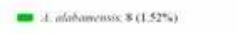 \\
\hline Texas & 0.0 & 0.0 & $=1$ Anomeat $140.1 \%$ \\
\hline Qatar & 0.0 & 0.0 & 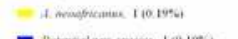 \\
\hline
\end{tabular}

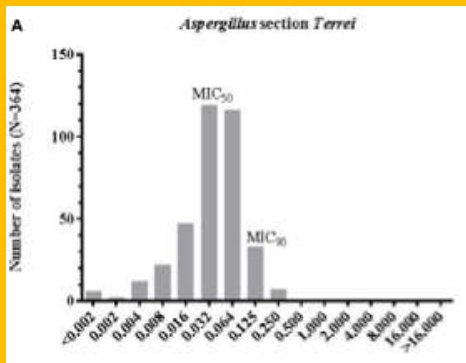

Posaconazole (ug m1.

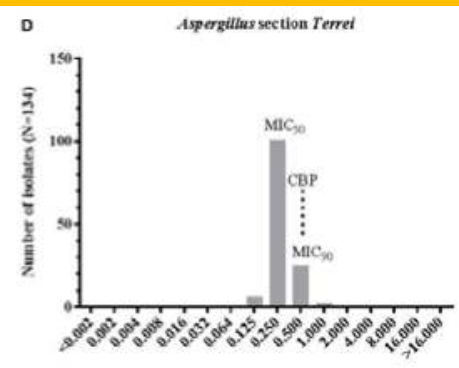

Posaconazole (urg m L)

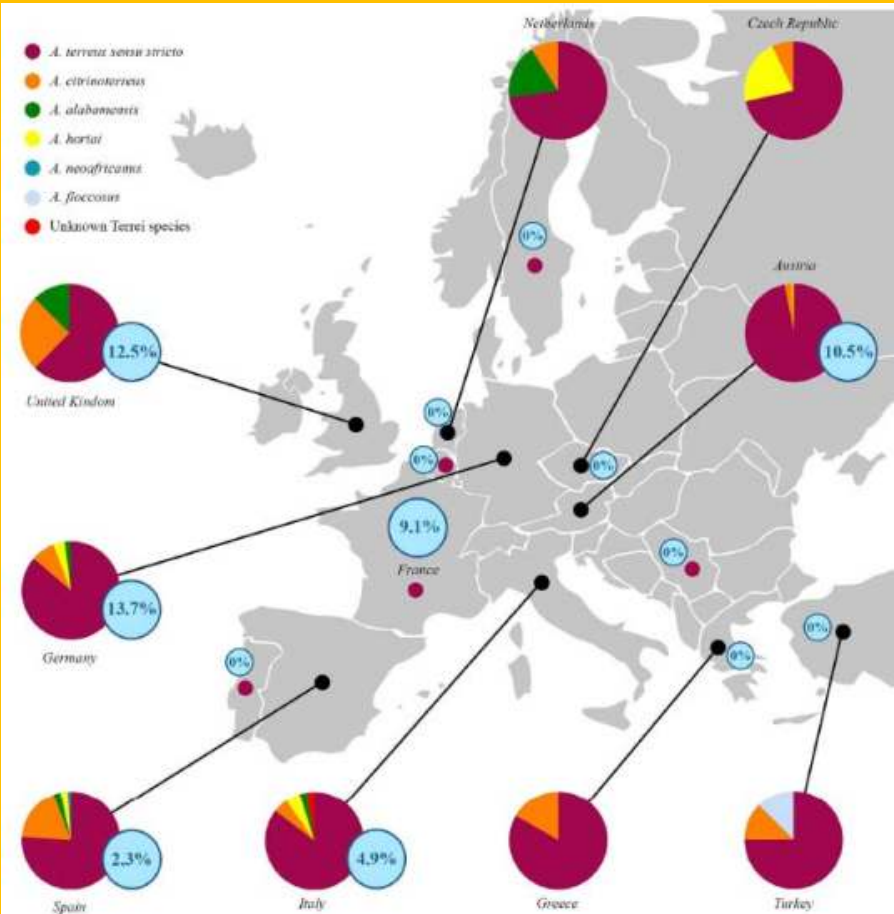

The majority of isolates were identified as Aspergillus terreus s.s. $(86.8 \%)$.

Posaconazole resistance in section Terrei isolates differed geographically and reached up to $13.7 \%$ in Germany.

The most affected amino acid position of the Cyp51A correlating with the posaconazole resistant phenotype was M217, which was found in the variation M217T and M217V.

\section{Conclusion}

A. terreus s.s. was most prevalent, followed by $A$. citrinoterreus

- Posaconazole was the most effective drug against all species of the section Terrei

- $5.4 \%$ of A. terreus s.s. were posaconazole-resistance

- Resistance against itraconazole was absent and rare for voriconazole 